\title{
The Efficacy of Pulsed Radiofrequency Treatment of Cervical Radicular Pain Patients
}

\author{
Young Moon Yoon, Seong Rok Han, Seung Jun Lee, \\ Chan Young Choi, Moon Jun Sohn, Chae Heuck Lee \\ Department of Neurosurgery, Ilsan Paik Hospital, Inje University College of Medicine, Goyang, Korea
}

Objective: Cervical radicular pain is defined as pain arising in the arm caused by irritation of a cervical spinal nerve or its roots. Although many treatment modalities are described in the literature, the available evidence for efficacy is not sufficient to allow definitive conclusions. The goal of this study was to establish the benefits and prognostic factors of pulsed radiofrequency (PRF) on the adjacent cervical dorsal root ganglia (DRG) of cervical radicular pain patients.

Methods: A retrospective study of PRF treatment of patients with cervical radicular pain was carried out. Two times diagnostic block of cervical DRG were performed before PRF. PRF was applied for 2 minutes at a setting of $2 \mathrm{~Hz}$ and $45 \mathrm{~V}$ by two times on the same targets, with the end point being an electrode tip temperature $42^{\circ} \mathrm{C}$. Numerical rating scale (NRS) score was evaluated post-treatment 2 week, 1 month, 3 months and 6 months, which were compared with pretreatment value. A successful outcome was defined that NRS change was improved more than $50 \%$ at 6 months.

Results: The mean age was 54 years. The success rate was $68 \%$ (15/22) after six months of follow-up. PRF induced complications were not observed. Between success and failure group, we do not find any positive outcome prognostic factor. Interestingly, PRF treatment on foraminal stenosis is better outcome than herniated cervical disc.

Conclusions: PRF on adjacent cervical DRG is effective and safe treatment option for cervical radicular pain patients. However, more long-term follow up and larger patients are needed to establish effectiveness PRF treatment on cervical radicular pain patients.

Key Words: Cervical radicular pain $\cdot$ Pulsed radiofrequency $\cdot$ Cervical dorsal root ganglia

\section{INTRODUCTION}

Cervical radicular pain is defined as pain arising in the upper limb with a sharp, shooting and lancinating character caused by ectopic activation of the nerve roots or other neuropathic mechanisms ${ }^{3)}$. Radicular pain is a symptom that is caused by ectopic impulse formation, while radiculopathy includes neurologic signs such as sensory or motor changes ${ }^{9)}$. These two disorders may occur simultaneously also ${ }^{9)}$. Although many treatment modalities are described, the available evidence for efficacy is not sufficient to allow definitive conclusions on

- Received: May 13, 2014 - Revised: June 29, 2014

- Accepted: July 16, 2014

Corresponding Author: Seong Rok Han, MD, PhD

Department of Neurosurgery, Ilsan Paik Hospital, Inje University 170 Juhwa-

ro, Ilsan-Seo-gu, Goyang 411-706, Korea

Tel: +82-31-910-7730, Fax: +82-31-915-0885

E-mail: hsrkmj@paik.ac.kr

$\otimes$ This is an Open Access article distributed under the terms of the Creative Commons Attribution Non-Commercial License (http://creativecommons.org/ licenses/by-nc/3.0/) which permits unrestricted non-commercial use, distribution, and reproduction in any medium, provided the original work is properly cited. the optimal therapy to be made ${ }^{10)}$.

Radiofrequency (RF) treatment, adjacent cervical dorsal root ganglia (DRG), was first described by van Kleef et al. ${ }^{8)}$. They reported good results and some side effects, which are transient neuritis and a loss of muscle strength in the hand ${ }^{8)}$. Due to these side effects and the possibility of deafferentation pain, pulsed radiofrequency (PRF) to the cervical DRG becomes in popularity.

The goal of this retrospective study is to evaluate the efficacy of the application of PRF treatment to adjacent cervical DRG in treatment of cervical radicular pain patients.

\section{MATERIALS AND METHODS}

\section{Patient Selection}

We retrospectively reviewed and analyzed 22 patients with cervical radicular pain patients who underwent PRF treatment at our institute between April 2012 and Nov 2013.

Cervical radicular pain is characterized by pain in the neck that radiates over the posterior shoulder into the arm and 
sometimes into the hand. The radiation follows a segmentspecific pattern. Pain originating from $\mathrm{C} 5$ radiates up to the upper arm, and pain from $\mathrm{C} 6$ and $\mathrm{C} 7$ radiates from the neck to the shoulder, the forearm, and the hand. All patients received X-ray and either cervical magnetic resonance imaging (MRI) or computed tomography (CT) study.

The inclusion criteria for this study were sustained segmental pain of over 4 on a numerical rating scale (NRS) score even after conservative management which included non-steroidal anti-inflammatory agents and physical therapy and clinical manifestations are corresponded with imaging findings also.

Exclusion criteria for this study were as follows: patients with a motor deficit or myelopathy, any other indications for surgical treatment which included either ruptured or extruded cervical disc. Severe ossification posterior longitudinal ligament patients are also excluded.

The selection of treatment level of cervical DRG was made according to the characterized cervical radicular pain and cervical MRI or CT findings.

\section{Diagnostic Blocks and PRF Application}

Before cervical PRF treatment, all patients underwent a diag- nostic cervical DRG procedure using 1-1.5 $\mathrm{mL}$ of $0.75 \%$ Naropine ${ }^{\circledR}$ (Ropivacaine hydrocholoride) by two times. Those patients who experienced a positive response to a diagnostic cervical DRG block were underwent PRF treatment.

PRF treatment was applied as the same manner and level as the diagnostics blocks. Skin was infiltrated with lidocaine 2\%. A RF generator (RFG 3C Plus, Radionics) was used with fluoroscopic guidance using C-arm. A 10-cm 22-gauge SMKC10 electrode with 10-mm active tip was placed adjacent the cervical DRG. Impedance was verified at 300 to $500 \Omega$ to confirm proper electrode placement and integrity of the RF system. The RF electrode was verified by electrical $50 \mathrm{~Hz}$ stimulation (sensory stimulation). During stimulation, a tingling sensation in the corresponding dermatome had to be obtained less than $0.8 \mathrm{~V}$. The electrode was repositioned if patient didn't experience any sensory manifestations. After confirmation adjacent cervical DRG, $0.5-1 \mathrm{~mL}$ of lidocaine $1 \%$ was injected through an electrode to obtain a profound local anesthesia. Two times PRF was applied for 120 seconds at a setting of $2 \mathrm{~Hz}$ and $45 \mathrm{~V}$, with the end point being an electrode tip temperature not exceeding $42^{\circ} \mathrm{C}$.

Patients were evaluated similarly at pretreatment, post-

Table 1. Summany of characteristics and results of the patients

\begin{tabular}{|c|c|c|c|c|c|c|c|c|c|c|c|c|}
\hline \multirow{2}{*}{ No. } & \multirow{2}{*}{ Sex } & \multirow{2}{*}{ Age } & \multirow{2}{*}{ Diagnosis } & \multirow{2}{*}{ No. of lesion } & \multicolumn{6}{|c|}{ NRS score } & \multirow{2}{*}{$50 \mathrm{~Hz}$ paresthesia $(\mathrm{M})$} & \multirow{2}{*}{$(\Omega)$} \\
\hline & & & & & Pre & $2 w$ & $1 \mathrm{~m}$ & $3 m$ & $6 \mathrm{~m}$ & Result & & \\
\hline 1 & $\mathrm{~F}$ & 43 & $\mathrm{HCD}$ & 2 & 6 & 2 & 2 & 1 & 0 & Excellent & 0.33 & 357.50 \\
\hline 2 & M & 81 & FS & 1 & 6 & 1 & 0 & 0 & 0 & Excellent & 0.60 & 321.00 \\
\hline 3 & $M$ & 44 & FS & 1 & 5 & 2 & 1 & 1 & 0 & Excellent & 0.20 & 320.00 \\
\hline 4 & M & 34 & $\mathrm{HCD}$ & 1 & 9 & 1 & 0 & 0 & 1 & Excellent & 0.35 & 490.00 \\
\hline 5 & M & 53 & $\mathrm{HCD}$ & 1 & 9 & 1 & 2 & 2 & 1 & Excellent & 0.60 & 392.00 \\
\hline 6 & $\mathrm{~F}$ & 58 & FS & 1 & 8 & 4 & 1 & 1 & 1 & Excellent & 0.40 & 345.00 \\
\hline 7 & $M$ & 66 & FS & 1 & 8 & 2 & 2 & 4 & 1 & Excellent & 0.50 & 390.00 \\
\hline 8 & $M$ & 53 & FS & 1 & 6 & 3 & 2 & 1 & 1 & Excellent & 0.80 & 480.00 \\
\hline 9 & $\mathrm{~F}$ & 53 & FS & 1 & 10 & 6 & 3 & 2 & 2 & Excellent & 0.40 & 440.00 \\
\hline 10 & M & 55 & $\mathrm{HCD}$ & 2 & 8 & 2 & 1 & 1 & 2 & Excellent & 0.55 & 415.00 \\
\hline 11 & M & 61 & $\mathrm{HCD}$ & 1 & 8 & 4 & 6 & 2 & 2 & Excellent & 0.70 & 385.00 \\
\hline 12 & M & 71 & FS & 1 & 9 & 3 & 4 & 1 & 3 & Good & 0.30 & 295.00 \\
\hline 13 & $\mathrm{~F}$ & 51 & $\mathrm{HCD}$ & 1 & 6 & 4 & 3 & 2 & 2 & Good & 0.60 & 330.00 \\
\hline 14 & $M$ & 56 & FS & 1 & 6 & 3 & 2 & 2 & 3 & Good & 0.40 & 340.00 \\
\hline 15 & M & 60 & $\mathrm{HCD}$ & 1 & 6 & 3 & 3 & 3 & 3 & Good & 0.40 & 470.00 \\
\hline 16 & $M$ & 43 & FS & 1 & 8 & 4 & 4 & 5 & 5 & Fair & 0.60 & 380.00 \\
\hline 17 & $\mathrm{~F}$ & 54 & $\mathrm{HCD}$ & 2 & 6 & 2 & 2 & 3 & 4 & Fair & 0.45 & 370.00 \\
\hline 18 & $\mathrm{~F}$ & 62 & $\mathrm{HCD}$ & 1 & 10 & 8 & 9 & 9 & 8 & Poor & 0.60 & 460.00 \\
\hline 19 & $\mathrm{~F}$ & 56 & $\mathrm{HCD}$ & 1 & 5 & 2 & 2 & 2 & 4 & Poor & 0.40 & 400.00 \\
\hline 20 & $\mathrm{~F}$ & 50 & $\mathrm{HCD}$ & 1 & 4 & 2 & 4 & 4 & 4 & Poor & 0.50 & 340.00 \\
\hline 21 & $\mathrm{~F}$ & 46 & $\mathrm{HCD}$ & 1 & 5 & 2 & 2 & 3 & 5 & Poor & 0.30 & 364.00 \\
\hline 22 & $\mathrm{~F}$ & 52 & $\mathrm{HCD}$ & 2 & 7 & 7 & 7 & 7 & 7 & Poor & 0.55 & 340.50 \\
\hline
\end{tabular}

No.: number, PRF: pulsed radiofrequency, NRS: numerical rating scale, w: weeks, m: month, M: Male, F: Female, HCD: herniated cervical disc, FS: foraminal stenosis, V: volts 
treatment 2 weeks, 1 month, 3 months and 6 months. During the examinations, cervical radicular pain was evaluated by NRS score. In order to validate the degree of change in pain reduction (change in NRS [\%] $=$ [scores at pretreatment-scores at post-treatment] /scores at pretreatment $\times 100$ ) is calculated. According to change of improvement NRS score at six months, patient satisfaction were divided by excellent $(\geq 75 \%$, improvement of NRS score), good ( $\geq 50 \%)$, fair $(\geq 25 \%)$ and poor $(<25 \%)$. Any complications were recorded during follow up period. Pain relief of $50 \%$ or more was defined as successful group. The other patients was defined as failures group. Statistical analysis was conducted using Medcalc ${ }^{\circledR}$ (Ver.9.0, Medcalc software, Belgium). Formal comparisons between two groups (successful vs. failure) were made using independent t-tests. p-value of less than 0.05 was regarded as statistically significant.

\section{RESULTS}

The mean age of the patients was $54 \pm 10$ years. $12(55 \%)$ patients were males and $10(45 \%)$ were females. Cervical MRI or CT findings revealed that 13 (59\%) patients had herniated cervical disc and $9(41 \%)$ had the foraminal stenosis. PRF on C5 DRG performed in $4(18 \%)$ patients. PRF on C6 DRG was done in $17(72 \%)$ patients. $5(22 \%)$ patients underwent PRF on C7. 4 (18\%) patients were treated PRF on two lesions. The other patients underwent single PRF treatment. The averages of NRS scores was declined from $7 \pm 1.7$ at pretreatment to $3.1 \pm 1.9$ (change in NRS [\%] $=59.3 \%$ ) at 2 weeks of posttreatment, $2.8 \pm 2.2(59.3 \%)$ at 1 month, $2.5 \pm 2.2(62.4 \%)$ at 3 months and $2.7 \pm 2.2(59.5 \%)$ at 6 months. Among 22 patients, 15 (68\%) patients were successes groups (improvement $\mathrm{NRS} \geq 50 \%$ at six months PRF treatment) and seven (32\%)

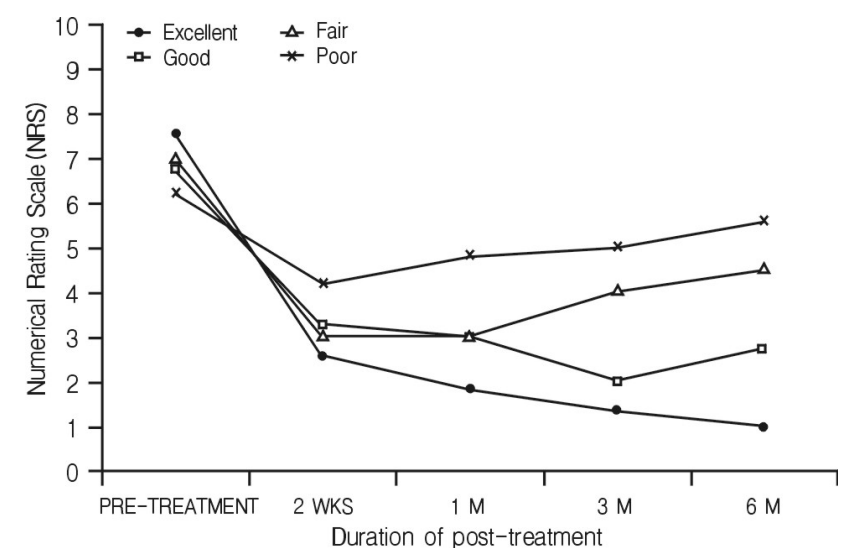

Fig. 1. The results of four groups (Excellent, Good, Fair and Poor) changes in average numerical rating scale scores after PRF treatment. patients were failure groups. This is summarized in Table 1 and Fig. 1. There were no complications related with PRF treatment during the follow-up period. Cervical DRG impedance mean was $382.9 \Omega$, which ranged from 290 to 490 . Between success and failure group, we do not find any successful outcome prognostic factor (Table 2). Change in NRS (\%) at 6 months, foraminal stenosis $(n=9)$ is $76.94 \pm 21.57 \%$ and herniated cervical disc $(n=13)$ is $47.52 \pm 37.13 \%$. Interestingly, PRF treatment on foraminal stenosis were better outcome than herniated cervical disc. However, there is no statistically significant ( $\mathrm{p}$-value $=0.13)$.

\section{DISCUSSION}

Cervical radicular pain is characterized by pain radiating from the neck over the posterior shoulder into the arm according to a particular segmental pattern corresponding with involvement of the spinal nerve segments C5, C6, or C7. A positive Spurling test has been demonstrated to be a valuable tool in the clinical diagnosis of cervical radicular pain ${ }^{7}$.

The principle of epidural administration of corticosteroids relies on the anti-inflammatory response induced by inhibition of the phospholipase $\mathrm{A}^{9)}$. Benyamin RM et al. ${ }^{1)}$ reported systematic review of cervical interlaminar epidural injections. The global conclusion of this systematic review is that interlaminar cervical epidural corticosteroid injections provide a significant effect on cervical radicular pain. However, sometimes interlaminar cervical epidural steroid injection may have major complications which included epidural hematoma and accidental subdural injection with, as a result, hypoventilation and hypotension ${ }^{9)}$.

RF treatment adjacent cervical DRG for cervicobrachial pain patients had been described by van Kleef et $\mathrm{al}^{8)}$. In their study, each of 20 consecutive patients with a history of at least 1 year of intractable chronic cervicobrachial pain were randomly assigned to one of two treatment groups (Sham group vs. $\mathrm{RF}$ treatment group). They suggested that a $67^{\circ} \mathrm{C} \mathrm{RF}$ lesion adjacent to the cervical DRG can result in a significant alleviation of pain in chronic cervicobrachial pain patients after 2

Table 2. Comparison of prognostic factors between success and failure group

\begin{tabular}{lccc}
\hline \hline \multicolumn{1}{c}{ Group $(\mathrm{n})$} & $\begin{array}{c}\text { Success } \\
\text { group (15) }\end{array}$ & $\begin{array}{c}\text { Failure } \\
\text { group (7) }\end{array}$ & p-value \\
\hline Age (years) & $55.93 \pm 11.48$ & $51.85 \pm 6.34$ & 0.15 \\
Pretreatment NRS & $7.33 \pm 1.54$ & $6.43 \pm 2.07$ & 0.34 \\
50 H paresthesia (Nolts) & $0.48 \pm 0.16$ & $0.49 \pm 0.11$ & 0.34 \\
Impedance $(\Omega)$ & $384.70 \pm 62.73$ & $379.21 \pm 41.46$ & 0.31 \\
\hline
\end{tabular}

$\mathrm{n}$ : number of patients, NRS: numerical rating scale 
months treatment. Slappendel et al. ${ }^{5)}$ reported the efficacy of RF lesion treatment of the cervical DRG in cervicobrachialgia. They investigated in 61 patients by a randomized prospective double blinded study. They did not find any difference between a group of RF treatment at $40^{\circ} \mathrm{C}$ compared with at $67^{\circ} \mathrm{C}$. Both groups shows that the visual analogue scale scores being significantly reduced 1.5 months and 3 months after the procedure. Above two randomized controlled trials showed limited evidence that RF of the cervical dorsal root is more effective than placebo in chronic cervical radicular pain. However, transient neuritis and/or a burning sensation in the treated spinal nerve were noted and a slight loss of muscle strength in the hand or arm on the treated side was reported ${ }^{5,8}$.

For this reason a modification of the technique, resulting in less neural damage, would be more attractive for chronic pain management. PRF has been described as a nondestructive alternative to radiofrequency thermo-coagulation for the management of chronic pain ${ }^{2}$. Although the mechanism of action is not completely understood, one of the prevailing theories postulates that the electrical fields reversibly disrupt the transmission of impulses across small unmyelinated fibers ${ }^{4,6)}$. The concept that PRF may produce inhibition of excitatory C-fiber responses using a phenomenon such as long-term depression ${ }^{2)}$. Maintaining the temperature at the tip of the electrode at $42^{\circ} \mathrm{C}$ that may allow the dissipation of heat, avoiding the complication of thermal injury, thereby decreasing post-procedure side effects $^{4,6}$.

Van Zundert et al. ${ }^{10)}$ reported that the effect of PRF treatment adjacent cervical DRG in chronic cervical radicular pain group showed a significantly better outcome than sham group at post-treatment 3 months.

Choi et al..$^{3)}$ reported that effect of PRF on refractory cervical radicular pain patients. In this report, 14 patients (66.7\%) after cervical PRF stimulation reported pain relief of 50\% or more at the 3-month and 12-month follow-up periods, respectively. 15 patients (71.4\%) were satisfied with their outcome at 12 months post-treatment.

Our study showed that the degree of change in pain reduction rates at 3 months, 6 months after treatment were $62.4 \%$ and $59.5 \%$, respectively. This study showed that the PRF treatment on adjacent cervical DRG appears to be relatively safe and effective treatment method. However, our study has some limitations. Absence of control group with similar characteristics and the small number of subjects. In the future, a controlled and randomized study design with a larger populations are needed.

\section{CONCLUSION}

PRF treatment of the adjacent cervical DRG in cervical radicular patients may provide pain relief of carefully selected patients with cervical radicular pain patients.

\section{REFERENCES}

1. Benyamin RM, Singh V, Parr AT, Conn A, Diwan S, Abdi S: Systematic review of the effectiveness of cervical epidurals in the management of chronic neck pain. Pain Physician 12(1):137157, 2009

2. Chao SC, Lee HT, Kao TH, Yang MY, Tsuei YS, Shen CC, et al: Percutaneous pulsed radiofrequency in the treatment of cervical and lumbar radicular pain. Surg Neurol 70(1):59-65, 2008

3. Choi GS, Ahn SH, Cho YW, Lee DG: Long-term effect of pulsed radiofrequency on chronic cervical radicular pain refractory to repeated transforaminal epidural steroid injections. Pain Med 13(3):368-375, 2012

4. Kroll HR, Kim D, Danic MJ, Sankey SS, Gariwala M, Brown M: A randomized, double-blind, prospective study comparing the efficacy of continuous versus pulsed radiofrequency in the treatment of lumbar facet syndrome. J Clin Anesth 20(7):534537, 2008

5. Slappendel R, Crul BJ, Braak GJ, Geurts JW, Booij LH, Voerman VF, et al: The efficacy of radiofrequency lesioning of the cervical spinal dorsal root ganglion in a double blinded randomized study: no difference between 40 degrees $\mathrm{C}$ and 67 degrees C treatments. Pain 73(2):159-163, 1997

6. Tekin I1, Mirzai H, Ok G, Erbuyun K, Vatansever D: A comparison of conventional and pulsed radiofrequency denervation in the treatment of chronic facet joint pain. Clin J Pain 23(6): 524-529, 2007

7. Van Boxem K, van Eerd M, Brinkhuizen T, Patijn J, van Kleef $\mathrm{M}$, van Zundert J: Radiofrequency and pulsed radiofrequency treatment of chronic pain syndromes: the available evidence. Pain Pract 8(5):385-393, 2008

8. Van Kleef M, Liem L, Lousberg R, Kessels F, Sluijter M: Radiofrequency lesion adjacent to the dorsal root ganglion for cervicobrachial pain: a prospective double blind randomized study. Neurosurgery 38(6):1127-1132, 1996.

9. Van Zundert J, Huntoon M, Patijn J, Lataster A, Mekhail N, van Kleef M: 4. Cervical radicular pain. Pain Pract 10(1):1-17, 2010.

10. Van Zundert J, Patijn J, Kessels A, Lamé I, van Suijlekom H, van Kleef M: Pulsed radiofrequency adjacent to the cervical dorsal root ganglion in chronic cervical radicular pain: a double blind sham controlled randomized clinical trial. Pain 127(1-2): 173-182, 2007. 